\title{
In vivo measurement and biological characterisation of the diabetes-associated mutant insulin p.R46Q (GInB22-insulin)
}

\author{
Julie Støy $^{1}$ - Jørgen Olsen ${ }^{2}$ - Soo-Young Park ${ }^{3,4}$ - Søren Gregersen ${ }^{5}$. \\ Claudia U. Hjørringgaard ${ }^{6}$. Graeme I. Bell ${ }^{3,4}$
}

Received: 21 December 2016 / Accepted: 31 March 2017 /Published online: 6 May 2017

(C) Springer-Verlag Berlin Heidelberg 2017

\begin{abstract}
Aims/hypothesis Heterozygous mutations in the insulin gene that affect proinsulin biosynthesis and folding are associated with a spectrum of diabetes phenotypes, from permanent neonatal diabetes to MODY. In vivo studies of these mutations may lead to a better understanding of insulin mutationassociated diabetes and point to the best treatment strategy. We studied an 18-year-old woman with MODY heterozygous for the insulin mutation p.R46Q (GlnB22-insulin), measuring the secretion of mutant and wild-type insulin by LC-MS. The clinical study was combined with in vitro studies of the synthesis and secretion of p.R46Q-insulin in rat INS-1 insulinoma cells.

Methods We performed a standard $75 \mathrm{~g}$ OGTT in the 18-yearold woman and measured plasma glucose and serum insulin
\end{abstract}

$\overline{\text { Julie Støy, Jørgen Olsen and Soo-Young Park contributed equally to this }}$ study.

Electronic supplementary material The online version of this article (doi:10.1007/s00125-017-4295-2) contains peer-reviewed but unedited supplementary material, which is available to authorised users.

Julie Støy

julistoe@rm.dk

1 Department of Internal Medicine and Endocrinology, Aarhus University Hospital, Nørrebrogade 44, 8000 Aarhus C, Denmark

2 ADME Department, Novo Nordisk, Måløv, Denmark

3 Department of Medicine, University of Chicago, Chicago, IL, USA

4 Department of Human Genetics, University of Chicago, Chicago, IL, USA

5 Department of Internal Medicine and Endocrinology, Aarhus University Hospital, Aarhus, Denmark

6 Protein \& Peptide Chemistry, Novo Nordisk, Måløv, Denmark (wild-type insulin and GlnB22-insulin), C-peptide, proinsulin, glucagon and amylin. The affinity of GlnB22-insulin was tested on human insulin receptors expressed in baby hamster kidney (BHK) cells. We also examined the subcellular localisation, secretion and impact on cellular stress markers of p.R46Q-insulin in INS-1 cells.

Results Plasma GlnB22-insulin concentrations were 1.5 times higher than wild-type insulin at all time points during the OGTT. The insulin-receptor affinity of GlnB22insulin was $57 \%$ of that of wild-type insulin. Expression of p.R46Q-insulin in INS-1 cells was associated with decreased insulin secretion, but not induction of endoplasmic reticulum stress.

Conclusions/interpretation The results show that beta cells can process and secrete GlnB22-insulin both in vivo and in vitro. Our combined approach of immunoprecipitation and LC-MS to measure mutant and wild-type insulin may be useful for the study of other mutant insulin proteins. The ability to process and secrete a mutant protein may predict a more benign course of insulin mutation-related diabetes. Diabetes develops when the beta cell is stressed because of increased demand for insulin, as observed in individuals with other insulin mutations that affect the processing of proinsulin to insulin or mutations that reduce the affinity for the insulin receptor.

Keywords Insulin gene $\cdot$ Maturity-onset diabetes of the young $\cdot$ Mutant insulin
Abbreviations
BHK Baby hamster kidney
eIF $2 \alpha$ Eukaryotic Initiation Factor $2 \alpha$
ER Endoplasmic reticulum
NDM Neonatal diabetes mellitus 


\section{Introduction}

Insulin, a central hormone in glucose homeostasis, is secreted from the pancreatic beta cells in a tightly regulated manner to maintain plasma glucose within a narrow range. Type 1 diabetes results from complete insulin deficiency arising as a consequence of autoimmune destruction of the beta cells, whereas type 2 diabetes develops because of peripheral insulin resistance and inadequate insulin secretion. Monogenic diabetes represents a distinct form of diabetes resulting from a single highly penetrant mutation in a gene central to the development and function of the pancreatic beta cells. To date, more than 20 genes have been implicated in monogenic diabetes [1].

Heterozygous missense mutations in the insulin gene cause monogenic disorders of glucose homeostasis through effects on beta cell function, processing of proinsulin to insulin or altered insulin-receptor affinity. Mutations in the insulin gene are associated with phenotypes ranging from the severe permanent neonatal diabetes (NDM), with complete insulin deficiency, to near-normal glucose homeostasis in familial hyperinsulinaemia [2-5]. MODY, an autosomal dominantly inherited form of diabetes with onset before 25 years of age, is another clinical manifestation of heterozygous insulin gene mutations [6-9].

Insulin gene mutations are a relatively common cause of NDM and, consequently, the pathophysiology of this form of diabetes has been studied in detail in cultured cells and in mouse models of insulin-related diabetes [2, 3, 10-14]. The effects of mutations associated with NDM include defects in cleavage of the signal peptide of preproinsulin as well as alteration of the three-dimensional structure of the mutant proinsulin, which impedes the transition of proinsulin through the endoplasmic reticulum (ER) leading to ER stress and, ultimately, cell death [15].

The insulin gene mutations found in individuals with MODY represent a subgroup of mutations that are not found in individuals with NDM. The pathophysiology of insulin gene mutations associated with MODY is poorly understood. The majority of these individuals have beta cell insulin secretory capacity, as suggested by variable treatment requirements ranging from no treatment to insulin therapy. It has been suggested that the effects of the MODY-associated mutations may mimic those of the NDM-associated mutations, but with a less detrimental effect on beta cell function $[15,16]$. If ER stress is part of the pathophysiology, we would anticipate gradually declining beta cell function and increasing insulin deficiency over the course of the disease. As only a few individuals with this form of MODY have been described, and none studied in detail, the effect of the mutant insulin protein on beta cell viability and function over time is uncertain. In contrast to individuals with NDM resulting from an insulin gene mutation, individuals with MODY have functioning beta cells, thus it is possible to assess the ability of the beta cells to process and secrete a mutant insulin protein. The best treatment strategy for these individuals to both achieve euglycaemia and preserve beta cell function is currently unknown, but it may emerge from detailed studies of the effects of MODYassociated insulin mutations on beta cell function in vivo and in vitro.

Here, we carried out a detailed clinical characterisation of an individual with MODY heterozygous for the insulin gene mutation p.R46Q together with in vitro characterisation of the effect of this mutation on beta cell function.

\section{Methods}

\section{Clinical studies}

The individual was admitted to the clinical research unit for a standard $120 \mathrm{~min} 75 \mathrm{~g}$ OGTT. She had fasted for $10 \mathrm{~h}$ and had omitted her insulin glargine (Lantus, Sanofi-Aventis, Paris, France) for $60 \mathrm{~h}$. An intravenous catheter was inserted into a cubital vein for blood sampling. Blood was sampled at $15 \mathrm{~min}$ intervals to measure plasma glucose. Serum insulin, proinsulin, glucagon, amylin and C-peptide were analysed at time points $-2,30,60$ and $120 \mathrm{~min}$. Details of the biochemical analyses are provided in the electronic supplementary material (ESM) Methods.

Sequencing of INS, HNF1A (also known as MODY3), HNF4A (MODY1), GCK (MODY2) and HNF1B (MODY 5) was performed as previously described $[2,17]$.

The individual provided informed consent. The regional ethics committee considered the project as a thorough clinical case evaluation and no formal registration with the committee was required (Region Midt, Denmark, request 71/2013).

\section{Isolation and characterisation of plasma insulin}

Immuno-purification and LC-MS Magnetic beads for insulin immunopurification from the individual's plasma was performed according to a standard protocol from the manufacturer (Invitrogen, Carlsbad, CA, USA). Additional details of the isolation of insulin are provided in the ESM Methods. LC-MS analysis of parent peptide was conducted using an LTQ Orbitrap Classic (ThermoScientific, Bremen, Germany). The HPLC system consisted of HPLC pumps from Agilent Technologies ([1100-series] Palo Alto, CA, USA) and an auto-sampler from CTC Analytics (Zwingen, Switzerland). A $20 \mu \mathrm{l}$ volume of sample was injected. The mass spectrometer was operated in positive ionisation mode (electrospray ionisation) and data were collected in the selected ionmonitoring mode from 1151 to $1171 \mathrm{~m} / \mathrm{z}$. For identification purposes, the samples were also run with a wider scan range, from 800 to $1500 \mathrm{~m} / \mathrm{z}$. Further details of the analysis are provided in the ESM Methods. 
Synthesis of GlnB22-insulin The insulin chains were synthesised using standard fluorenylmethyloxycarbonyl (FMOC)based solid-phase peptide synthesis and an automated peptide synthesiser (Prelude, PTI Technologies, Oxnard, CA, USA) giving GlnB22-human insulin in a $2.2 \%$ isolated yield. Additional details of the synthesis of GlnB22-insulin are provided in the ESM Methods.

Plasma calibration standards for quantification of GInB22-insulin The plasma calibration standards underwent the same immunoprecipitation procedure as the individual's samples. Plasma calibration standards were constructed by adding both human wild-type insulin and GlnB22-insulin to plasma from LYD (crossbred Landrace $\times$ Yorkshire $\times$ Duroc) pigs (pool of plasma from in-house LYD pigs). Plasma from LYD pigs was used as surrogate plasma for quantification of human insulin as there were endogenous levels of human insulin in blank human plasma. An initial comparison showed that LYD pig plasma and human plasma were similar with respect to analysis of GlnB22-insulin and internal standard and, in addition, the same results were obtained for the highest calibration standards of human insulin in both sources of plasma. Plasma calibration standards were prepared in porcine plasma at $6.0,12.1,24.2,60.4,121,242,604$ and $1208 \mathrm{pmol} / 1$ for wildtype insulin and 4.0, 7.9, 15.9, 39.7, 79.3, 159, 397 and $793 \mathrm{pmol} / \mathrm{l}$ for GlnB22-insulin. Two calibration curves were prepared for wild-type- and GlnB22-insulin, and calibration curves were analysed before and after the analysis of the individual's samples. A process method was constructed by the use of XCalibur (2.1, ThermoScientific) in which the most dominant isotopes of each insulins were summed with a mass accuracy at $5 \mathrm{ppm}$. Calibration curves were fitted with a quadratic curve fit (1/X). The estimated lower limit of quantification was $12 \mathrm{pmol} / 1$ for wild-type human insulin and $16 \mathrm{pmol} / 1$ for GlnB22-insulin. The standards analysed after the samples served as quality-control samples. Overall, back-calculated concentrations of all plasma calibration standards and qualitycontrol samples were within $85-115 \%$ of the nominal value at each concentration level.

\section{In vitro studies of p.R46Q-insulin}

Insulin-receptor binding assay The affinity of GlnB22insulin for the human insulin receptor purified from BHK cells was determined as described by Glendorf et al [18]. The binding affinity of the GlnB22-insulin was expressed relative to that of wild-type insulin [ $\mathrm{IC}_{50}$ (wild-type insulin)/ $\mathrm{IC}_{50}$ $($ GlnB22-insulin $) \times 100 \%]$ in three independent experiments

cDNA constructs Human insulin cDNA was cloned in pcDNA3.1 (+) and mutations were introduced by overlap extension PCR mutagenesis using primers (forward; 5'-TAGT GTGCGGGGAACAAGGCTTCTTCTACAC- ${ }^{\prime}$ and reverse;
5'-GTGTAGAAGCCTTGTTCCCCGCACACTA-3') for p.R46Q and the sequence was confirmed by DNA Sanger sequencing [12].

Cell culture and subcellular localisation of wild type and mutant insulin Rat INS- 1 insulinoma cells $\left(1 \times 10^{6}\right)$ were cultured on glass cover slips in a six-well plate and transfected with $4.0 \mu \mathrm{g}$ of pcDNA3.1 (vector), wild-type or mutant human preproinsulin (p.R46Q or p.C96Y) cDNA together with $0.5 \mu \mathrm{g}$ of constructs expressing ER-localised monomeric red fluorescent protein (ER-mRFP) or an enhanced cyan fluorescent protein (ECFP) as a marker for the Golgi.

Measurement of C-peptide, proinsulin and insulin in cell lysates and media Cells were cultured in six-well plates. Twenty-four hours post-transfection, cells were washed in PBS and then cultured for $4 \mathrm{~h}$. The media was collected and centrifuged and human C-peptide was measured using an ELISA kit (Millipore, St Charles, MO, USA; EZHCP-20K). The cells were washed with PBS and harvested with a cell scraper in $150 \mu \mathrm{l}$ of lysis buffer. The lysate was sonicated for $10 \mathrm{~s}$ and then centrifuged at $13,362 \mathrm{~g}$ for $20 \mathrm{~min}$ at $4^{\circ} \mathrm{C}$. The supernatant was removed and assayed for human C-peptide as described above.

Western blot analysis Twenty-four hours post transfection, cells cultured in a six-well plate were rinsed and then dissolved in lysis buffer (Millipore, 524625). Fifteen $\mu \mathrm{g}$ of total protein from cell lysates were separated on a $15 \%$ SDS-PAGE and transferred to a PVDF membrane (Amersham Hybond-P PVDF Transfer Membrane; GE Healthcare, Piscataway, NJ). The levels of phosphorylated and total $\operatorname{eIF} 2 \alpha$ were measured using rabbit polyclonal anti-phospho-eIF $2 \alpha$ (Sigma, St Louis, MO, USA; E2151; 1000 dilution) and anti-eIF2 $\alpha$ antibodies (Santa Cruz Biotechnology; Dallas, TX, USA; sc11386; 1/1000 dilution), respectively. The blot was developed with Amersham ECL Western Blotting Detection Reagents after incubation for $1 \mathrm{~h}$ with HRP-conjugated secondary antibody, donkey anti-rabbit IgG, (GE Healthcare, NA934; 1/5000 dilution). Band intensity was quantified using the Gel Analysis package in ImageJ Software (NIH).

Additional details of the in vitro studies, including description of the insulin-receptor affinity study, human insulin cDNA constructs, cell culture, the evaluation of the subcellular localisation of wild-type and mutant insulin, measurement of C-peptide, proinsulin and insulin in cell lysates and media, and western blotting are provided in the ESM Methods.

\section{Statistical analyses}

In vitro results are presented as the mean $\pm \mathrm{SEM}$. Betweengroup differences were assessed using an unpaired $t$ test. A $p$ value below 0.05 was considered significant. 


\section{Results}

\section{Clinical characteristics of an individual with MODY resulting from the insulin mutation p.R46Q}

We studied a woman of Danish-Indian ancestry diagnosed with diabetes at 15 years of age. The woman had consulted her general practitioner for a suspected mild eating disorder. A routine biochemical evaluation revealed an $\mathrm{HbA}_{1 \mathrm{c}}$ of $6.5 \%$ $(48 \mathrm{mmol} / \mathrm{mol})$. The clinical characteristics of the individual are presented in Table 1. The woman is lean with a slim waist, has normal blood pressure and lipid profile and there is no sign of acanthosis nigricans. There is a family history of diabetes: impaired fasting glucose in her Indian father (age 54 years, BMI $21 \mathrm{~kg} / \mathrm{m}^{2}, \mathrm{HbA}_{1 \mathrm{c}} 6.1 \%$ [43 mmol/mol] ) and paternal uncle; and diagnosed type 2 diabetes in her paternal grandparents. The woman is otherwise healthy. Screening for mutations in HNF1A, HNF4A, GCK and HNF1B was negative. The woman was found to be a heterozygous carrier of a non-synonymous mutation in the insulin gene: $p$.Arg46Gln. Her parents were not carriers of the insulin gene mutation, suggesting it was de novo in origin.

Following the initial diagnosis of diabetes, the individual maintained acceptable glycaemic control with lifestyle interventions alone $\left(\mathrm{HbA}_{1 \mathrm{c}}<7 \%\right.$ [53 $\left.\left.\mathrm{mmol} / \mathrm{mol}\right]\right)$. After 2 years, glycaemic control deteriorated, with $\mathrm{HbA}_{1 \mathrm{c}}$ exceeding $7.5 \%$ $(58 \mathrm{mmol} / \mathrm{mol})$. The individual was started on a once-daily injection of insulin glargine (Lantus) (22 U/day). Acceptable glycaemic control was maintained for 2 years with this treatment regimen. At 4 years after diagnosis, glycaemic control was again deteriorating. Multiple-injection therapy with 8-14 U insulin aspart (Novorapid) and $22 \mathrm{U}$ insulin glargine (Lantus) was initiated. The woman's most recent $\mathrm{HbA}_{1 \mathrm{c}}$ is
$10.3 \%(89 \mathrm{mmol} / \mathrm{mol})$, reflecting her variable compliance. Her weight has remained stable since diagnosis and no latediabetic complications have developed.

The detailed clinical assessment of the individual was performed 3 years after diabetes was diagnosed, when $\mathrm{HbA}_{1 \mathrm{c}}$ was $7.5 \%$ (58 mmol/mol). Fasting venous glucose was $6.2 \mathrm{mmol} / \mathrm{l}$, with a maximum of $15.4 \mathrm{mmol} / 1120 \mathrm{~min}$ after ingestion of $75 \mathrm{~g}$ of D-glucose. Serum insulin, proinsulin, glucagon, C-peptide and amylin were determined at time points $-2,30$, 60 and $120 \mathrm{~min}$ (Table 2). Continuous glucose monitoring was performed shortly after the examination (ESM Fig. 1).

\section{Characterisation of insulin from the individual}

Identification of GInB22-insulin in plasma According to ELISA results, the woman had total serum insulin concentrations ranging from $22 \mathrm{pmol} / \mathrm{l}$ (fasting) to $182 \mathrm{pmol} / 1$ (time 120 min during the OGTT). The relative contribution of wild-type and GlnB22-insulin to these concentrations was unknown, i.e. was the woman exclusively secreting wild-type insulin or a mixture of wild-type and GlnB22-insulin? To address this issue, an immunoprecipitation method was developed to purify and enrich the plasma insulin samples, which allowed LC-MS to be used for identification and quantification of intact GlnB22- and wild-type human insulin. The immunoprecipitation procedure used a monoclonal antibody that binds to an epitope in the region of the loop in the A-chain, as described by Andersen et al [19]. An MS spectrum showing detectable levels of GlnB22-insulin from LC-MS analysis of a sample taken at 120 min during the OGTT is shown in ESM Fig. 2a. ESM Fig. 2b shows the identification of human insulin.
Table 1 Clinical characteristics of the individual with MODY in this study

\begin{tabular}{llll}
\hline Characteristic & Current & At time of the study & At onset of diabetes \\
\hline Age $($ years $)$ & 19 & 18 & 15 \\
$\mathrm{BMI}\left(\mathrm{kg} / \mathrm{m}^{2}\right)$ & 18.6 & 19.6 & 17 \\
$\mathrm{HbA}_{1 \mathrm{c}}(\mathrm{mmol} / \mathrm{l})$ & 89 & 58 & 48 \\
$\mathrm{HbA}_{1 \mathrm{c}}(\%)$ & 10.3 & 7.5 & 6.5 \\
Insulin dosage $\left(\mathrm{U} \mathrm{kg}^{-1}\right.$ day $\left.^{-1}\right)$ & 0.8 & 0.4 & Hyperglycaemia \\
Clinical manifestation & & & 0.32 \\
C-peptide $(\mathrm{nmol} / \mathrm{l})^{\mathrm{a}}$ & & Negative \\
Anti-GAD65 antibodies & & & \\
Birthweight/height & $3340 \mathrm{~g} / 52 \mathrm{~cm}$ & & \\
Ethnicity & Danish-Indian & & \\
Family history of diabetes & Yes & \\
Other health issues & Eating disorder & & \\
\hline
\end{tabular}

\footnotetext{
${ }^{a}$ Normal interval $0.21-1.15 \mathrm{nmol} / 1$

${ }^{\mathrm{b}}$ Father $\left(\mathrm{HbA}_{1 \mathrm{c}} 43 \mathrm{mmol} / \mathrm{mol}\right)$ and paternal uncle $\left(\mathrm{HbA}_{1 \mathrm{c}} 41 \mathrm{mmol} / \mathrm{mol}\right)$ with impaired glucose tolerance; paternal grandfather and grandmother with type 2 diabetes (on insulin)
} 
Table 2 Glucose and hormone concentrations during the OGTT

\begin{tabular}{|c|c|c|c|c|c|c|c|c|c|c|}
\hline \multirow[t]{2}{*}{ Variable } & \multicolumn{9}{|c|}{ Time (min) } & \multirow[t]{2}{*}{ Normal range, fasting } \\
\hline & -2 & 15 & 30 & 45 & 60 & 75 & 90 & 105 & 120 & \\
\hline Glucose (mmol/l) & 6.2 & 7.7 & 11.0 & 13.8 & 13.4 & 13.0 & 14.8 & 15.2 & 15.4 & $<6.1$ \\
\hline Total insulin (pmol/l), ELISA & 22 & & 92 & & 169 & & & & 182 & $23-68^{\mathrm{a}}$ \\
\hline $\begin{array}{l}\text { Wild-type insulin } \\
\text { (pmol/l), LC-MS }\end{array}$ & $<12$ & & 44 & & 74 & & & & 86 & - \\
\hline GlnB22-insulin (pmol/1), LC-MS & $<16$ & & 72 & & 128 & & & & 155 & - \\
\hline C-peptide (pmol/l) & 167 & & 464 & & 989 & & & & 1429 & $153-776^{\mathrm{a}}$ \\
\hline Glucagon (pg/ml) & 57 & & 53 & & 100 & & & & 48 & $19-78^{\mathrm{a}}$ \\
\hline Proinsulin (pmol/l) & 1.45 & & 4.66 & & 12.75 & & & & 24.56 & $1.04-10.53^{\mathrm{a}}$ \\
\hline Amylin (pmol/1) & 4.07 & & 5.31 & & 8.53 & & & & 9.17 & N/A \\
\hline Insulin/C-peptide ratio & 0.13 & & 0.20 & & 0.17 & & & & 0.13 & $0.05-0.25^{\mathrm{a}}$ \\
\hline HOMA-B $(\%)^{\mathrm{b}}$ & 36.2 & & & & & & & & & - \\
\hline HOMA-IR ${ }^{\mathbf{b}}$ & 0.43 & & & & & & & & & $0.35-1.25^{\mathrm{a}}$ \\
\hline
\end{tabular}

${ }^{\text {a }}$ Range for 29 healthy women examined in the medical research laboratories as part of another project (same assays and laboratory technician)

${ }^{\mathrm{b}}$ HOMA-B and HOMA-IR were calculated using an online available calculator (https://www.dtu.ox.ac.uk/homacalculator/; accessed 1 February 2017) N/A, not appropriate

\section{Quantification of wild-type and GInB22-insulin in plasma} Following the detection of GlnB22-insulin in plasma from the woman, absolute concentrations of wild-type and GlnB22insulin in plasma were determined at times $-2,30,60$ and 120 min during the OGTT. Standard curves for wild-type insulin and GlnB22-insulin were constructed for quantification purposes.

The LC-MS method was identical to the method described for identification of GlnB22-insulin, with the exception that the scan range was $1151-1171 \mathrm{~m} / \mathrm{z}$ to lower the limit of quantification. The method was qualified to cover wild-type insulin from $12 \mathrm{pmol} / 1$ to $1208 \mathrm{pmol} / \mathrm{l}$ and $\mathrm{GlnB} 22$-insulin from $16 \mathrm{pmol} / 1$ to $793 \mathrm{pmol} / \mathrm{l}$. An example of the analysis is shown in ESM Fig. 3.

Plasma concentration data for wild-type and GlnB22insulin as determined by LC-MS are included in Table 2. In plasma sampled prior to the glucose infusion, only trace levels of GlnB22-insulin were detected with plasma concentration below the lower limit of quantification of $16 \mathrm{pmol} / \mathrm{l}$.

\section{In vitro characterisation of p.R46Q-insulin}

\begin{abstract}
Affinity of GlnB22-insulin for the human insulin receptor The affinity of GlnB22-insulin for the human insulin receptor prepared from BHK cells was determined as described by Glendorf et al [18]. The receptor affinity of GlnB22-insulin was tested in triplicate, giving a mean affinity of $57.2 \%$ $(53.1-61.7 \%)$ relative to wild-type insulin. An example of the insulin-receptor binding curve of GlnB22-insulin is shown in ESM Fig. 4.
\end{abstract}

Subcellular localisation of wild-type and p.R46Q human insulin We used human C-peptide as a marker for human insulin as they are co-localised in the secretory granules of pancreatic beta cells and as antibodies to human insulin cross-react with the rat insulin made by the INS-1 cells (Fig. 1). Human C-peptide antiserum also detects human preproinsulin and proinsulin. As a positive (mutant) control for the localisation of a misfolded mutant human proinsulin, INS- 1 cells were transfected with the NDM-associated insulin mutation p.C96Y that is retained in the ER [12]. The INS-1 cells were co-transfected with constructs encoding an ERlocalised red fluorescent protein and a Golgi-localised enhanced cyan fluorescent protein to identify these cellular compartments.

INS-1 cells expressing the wild-type insulin construct showed a distinct punctate pattern in the periphery of the cells, indicating that $\mathrm{C}$-peptide was localised in secretory granules.

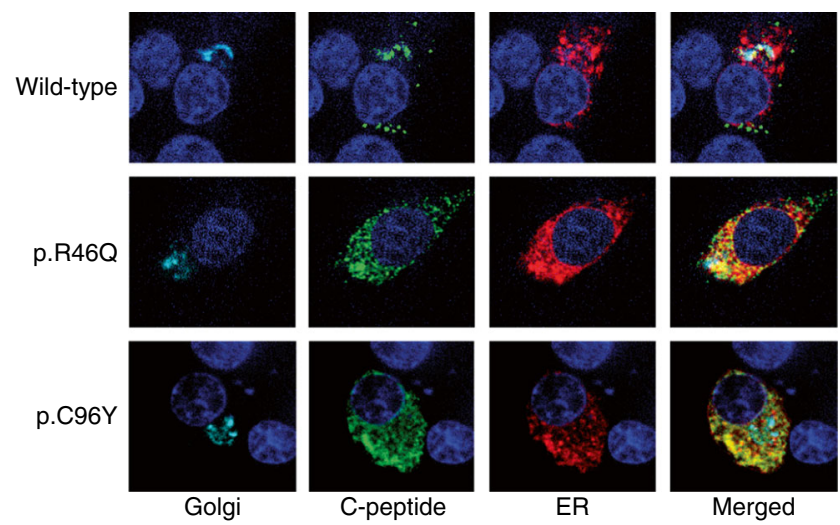

Fig. 1 Subcellular localisation of human C-peptide immunoreactivity in INS-1 cells. Human C-peptide immunoreactive protein is shown in green, the ER is shown in red and the Golgi is light blue (cyan). Nuclei stained with DAPI are dark blue. Yellow represents co-localisation of C-peptide and ER. The data are representative of three independent experiments 
As expected, INS-1 cells expressing the mutation p.C96Y had a markedly different appearance, with the C-peptide being localised in a dilated ER. The appearance of INS-1 cells expressing the mutation p.R46Q fell between that of those expressing wild-type insulin and those with p.C96Y-insulin, with C-peptide immunostaining in a slightly expanded ER as well as in secretory granule-like structures.

Secretion of human insulin in INS-1 cells We examined the human C-peptide content of the cells and media $24 \mathrm{~h}$ posttransfection during a $4 \mathrm{~h}$ static incubation in the presence of $5.5 \mathrm{mmol} / 1$ glucose. C-peptide was detectable in the media of cells expressing wild-type and p.R46Q-insulin but not p.C96Y-insulin (Fig. 2a), confirming the localisation of some of the p.R46Q-insulin to secretory granules. Co-expression of wild-type and p.R46Q-insulin to mimic the heterozygous genotype of the woman was associated with reduced C-peptide immunoreactivity in both the media and cell extract, suggesting suppression of biosynthesis and processing of the wildtype insulin by the mutant protein (Fig. 2a).

We also examined the effect of the mutant protein on insulin synthesis and secretion by co-expressing increasing amounts of the p.R46Q cDNA $(0.5,1.0$ and $2.0 \mu \mathrm{g})$ with a constant amount of wild-type insulin cDNA ( $2 \mu \mathrm{g}$; Fig. 2b). Previous studies have shown a dominant negative effect of the mutant p.C96Yinsulin on wild-type insulin biosynthesis and secretion [12]. We observed lower C-peptide concentrations in cells and media coexpressing wild-type and p.R46Q-insulin in a 1:1 ratio (Fig. 2a), whereas transfection with lower ratios of wild-type and p.R46Q-insulin cDNAs did not significantly affect

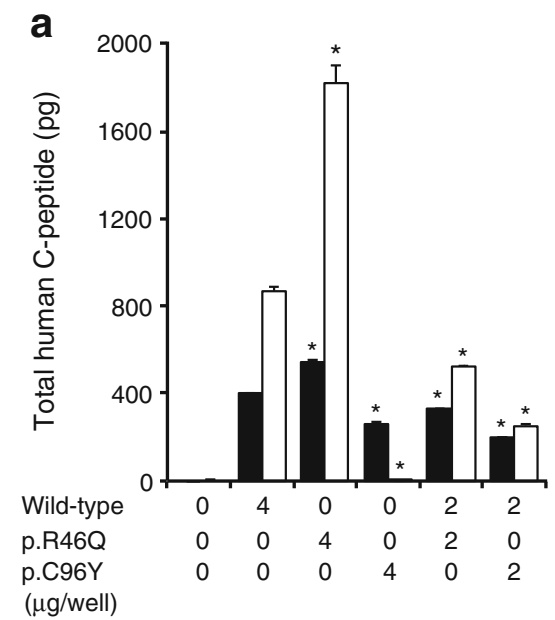

Fig. 2 (a) Synthesis and secretion of human C-peptide in INS-1 cells. Human C-peptide was measured after a $4 \mathrm{~h}$ static incubation in the presence of $5.5 \mathrm{mmol} / 1$ glucose. INS-1 cells were transfected with $4 \mu \mathrm{g}$ DNA from wild-type, mutant p.R46Q or p.C96Y-insulin constructs (columns two, three and four, respectively) as well as $2 \mu \mathrm{g}$ each of wild-type and p.R46Q or p.C96Y (columns five and six, respectively) constructs to mimic the heterozygous genotype of individuals carrying these mutations. The results are the mean \pm SEM of three independent experiments and are expressed as total C-peptide level in the cell extract and media.
C-peptide levels in the media and cell extracts (Fig. 2b). The effect of p.R46Q-insulin on C-peptide levels was less than that observed with p.C96Y in 1:1 ratio with wild-type (Fig. 2a).

Endoplasmic reticulum stress in INS1-cells expressing mutant insulin ER stress leads to increased phosphorylation of elongation factor $2 \alpha$ (eIF $2 \alpha$ ). Western blotting showed increased phosphorylation in INS-1 cells co-expressing p.C96Y and wild-type insulin as well as in cells treated with the ER stress inducer thapsigargin. Expression of p.R46Q and wild-type insulin either alone or in combination did not lead to increased phosphorylation of eIF $2 \alpha$, a result consistent with the C-peptide immunostaining of transfected cells showing only a modest expansion of the ER (Fig. 3).

\section{Discussion}

The woman with p.R46Q-associated diabetes had, 3 years after diabetes diagnosis, partially preserved insulin secretion, with fasting glucose levels in the impaired fasting glucose range increasing to the diabetic range after oral glucose challenge. The secretion of wild-type insulin and GlnB22-insulin increased in response to increasing plasma glucose, showing that both insulin proteins were secreted in a glucose-dependent manner via the regulated pathway of the beta cells.

Despite maintaining a normal body weight and an active lifestyle, the treatment requirements of the woman were gradually increasing, from no pharmacological treatment to multipleinjection insulin therapy. The cause of this apparent decline in

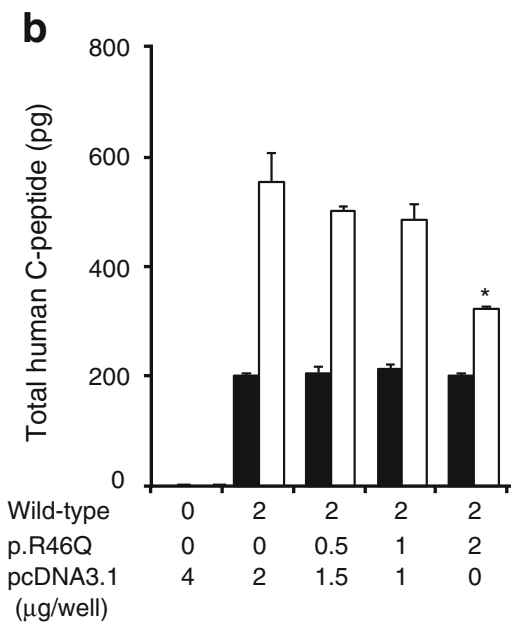

$* p<0.05$ vs $4 \mu \mathrm{g}$ of wild-type insulin alone. (b) Dominant negative effect of p.R46Q-insulin on expression of wild-type human insulin in INS-1 cells. INS1-cells were transfected with $2 \mu \mathrm{g}$ wild-type insulin cDNA and increasing amounts of p.R46Q-encoding cDNA (0, 0.5, 1.0 and $2.0 \mu \mathrm{g})$. The results are presented as mean \pm SEM of three independent experiments and expressed as total C-peptide levels in cell extract and media. $* p<0.05$ vs $2 \mu$ g wild-type insulin alone. Black bars, cell extract; white bars, media 
Fig. 3 (a, b) Western blot analysis of eIF $2 \alpha$

phosphorylation in $15 \mu \mathrm{g}$ cell lysate after $24 \mathrm{~h}$ incubation of cells transfected with wild-type (4 $\mu$ g DNA), p.R46Q (4 $\mu \mathrm{g}$ DNA), wild-type/p.R46Q (2 $\mu \mathrm{g}$ DNA of each), p.C96Y (4 $\mu \mathrm{g}$ DNA) and wild-type/p.C96Y ( $2 \mu \mathrm{g}$ DNA of each). INS-1 cells were exposed to $1 \mathrm{mmol} / 1$ thapsigargin for $3 \mathrm{~h}$ as a control to induce ER stress. The results are presented as mean \pm SEM of three independent experiments.

${ }^{*} p<0.05$ vs wild-type
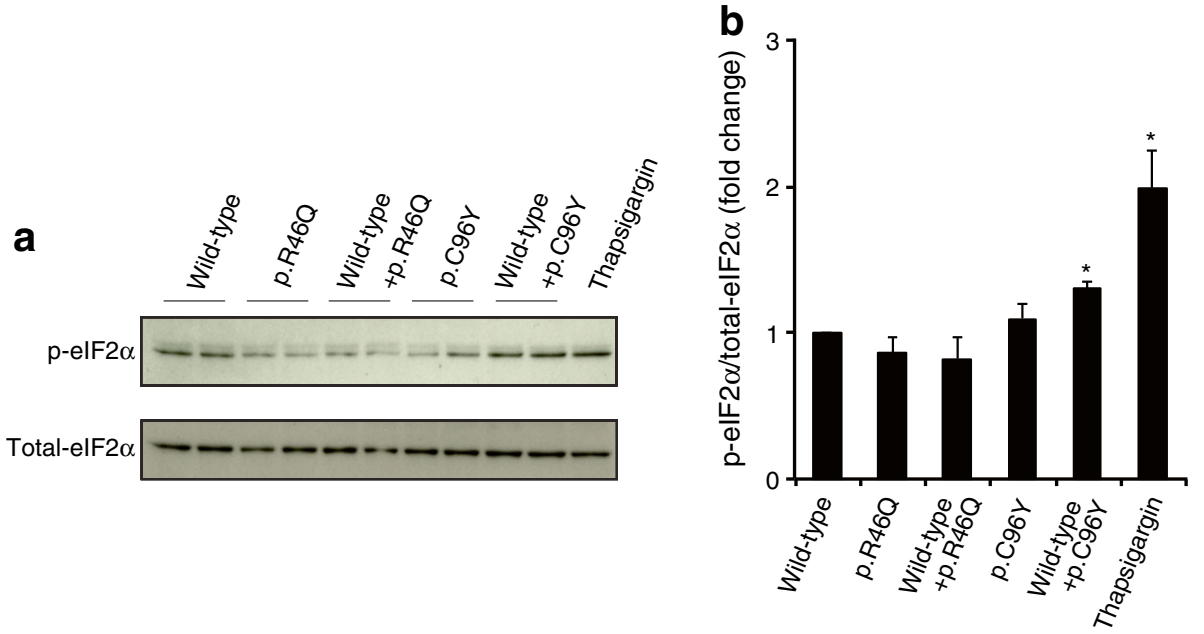

beta cell function may relate to mutation-specific effects on beta cell function over time. The family history of type 2 diabetes may indicate that other genetic factors impact beta cell function. Notably, glycaemic control continued to deteriorate despite intensification of the insulin treatment. There were considerable compliance issues, with non-adherence to the dietary recommendations and insulin treatment; we are uncertain of the woman's actual daily insulin dosage. Although the individual has never experienced diabetic ketoacidosis and her C-peptide level remains in the normal range 3 years after diagnosis, it would be of interest to measure pancreatic autoantibodies to rule out the development of autoimmune type 1 diabetes in addition to monogenic diabetes. The p.R46Q-insulin mutation has been identified in two additional families with MODY, one from Norway and the other from the Czech Republic [6, 7]. The seven carriers had disease duration of 4 years to 43 years, with treatment requirements ranging from diet to insulin treatment. The affected family members of the Norwegian family had excellent glycaemic control, with $\mathrm{HbA}_{1 \mathrm{c}} 5.8 \%$ (40 mmol/mol), although the individual with the longest disease duration of 43 years had developed diabetic neuropathy $[6,20]$. The individual in the current study fulfils only two of the three MODY criteria proposed by Tattersall in 1974 (early-onset diabetes and detectable C-peptide 3 years after diagnosis), whereas the mutation presented de novo.

Using LC-MS, we demonstrated that the woman in this study synthesised and secreted both wild-type insulin and GlnB22-insulin, with serum concentrations of GlnB22insulin up to 1.5 times higher than those of wild-type insulin. The reduced receptor affinity of GlnB22-insulin (57\% relative to human insulin), and hence the reduced insulin-receptormediated clearance of GlnB22-insulin, may explain its higher serum levels. Our findings have the same directional effects as those of Krizkova et al, though they detected a more pronounced negative effect of GlnB22-insulin on receptor affinity and biological activity [21]. Amino acid B22 is not directly engaged in binding insulin to its receptor, though amino acids
B20-23 assist in binding insulin to its receptor through a hinge-like rotation of the insulin B-chain enabling alignment of the receptor-binding subunits of the A- and B-chain with the insulin receptor [22]. This hinge-like function of B20-23 seems clinically relevant, as dysfunction imposed by a mutation, as in our individual, reduces the biological effect of the secreted insulin and results in diabetes.

To further examine the pathophysiology of p.R46Q, we performed a series of in vitro studies in INS-1 cells. Immunostaining using a human C-peptide-specific antibody in cells expressing p.R46Q-insulin showed localisation in secretory granules, suggesting it can enter the secretory pathway (Fig. 1), a result confirmed by the presence of C-peptide in media (Fig. 2a). Coexpression of wild-type and p.R46Q proteins in a 1:1 ratio, corresponding to the heterozygous carrier state of the woman, was associated with a $40 \%$ reduction in the C-peptide levels in the media, suggesting that p.R46Q impairs beta cell function. The reduced biological activity of GlnB22-insulin and the impaired beta cell function may both contribute to the pathophysiology of diabetes resulting from $p$. R46Q-insulin.

The treatment requirements of individuals with disorders of glucose homeostasis resulting from heterozygous mutations in the insulin gene are variable, and treatment should ideally be tailored to fit the effects of the specific mutation. Individuals affected by NDM caused by heterozygous insulin gene mutations have minimal endogenous insulin secretion and consequently they are treated with insulin; treatments aimed at reducing the toxic effects of the mutant insulin on beta cells have been suggested as a future therapeutic strategy, as this would preserve the beta cells and allow for synthesis and secretion of insulin derived from the wild-type healthy allele of the insulin gene [15]. In the woman in this study, who has MODY resulting from the insulin mutation p.R46Q, basal insulin secretion 3 years after diabetes onset was sufficient to maintain blood glucose in the non-diabetic impaired fasting glucose range. During glucose challenge, however, the insulin deficit became manifest. This suggests that treatment should 
aim to support the endogenous insulin secretion when insulin demands are high, i.e. around meal times. Future mutationspecific treatments, by means other than exogenous insulin administration, could include suppression of synthesis of the mutant insulin, thereby reducing the dominant negative effect of the mutant insulin on overall insulin secretion.

Here, we combined a detailed clinical characterisation of a woman with diabetes caused by the insulin gene mutation p.R46Q with in vitro studies of INS-1 cells expressing the identical mutation. We found that beta cells can process and secrete GlnB22-insulin both in vivo and in vitro, but expression of p.R46Q impairs beta cell function. Furthermore, we found that GlnB22-insulin has reduced insulin-receptor affinity.

Our combined approach of immunoprecipitation and LC-MS to measure mutant and wild-type insulin may be useful for the study of other mutant insulin proteins, such as those expressed in individuals with MODY with other insulin gene mutations or in those carrying NDM-associated mutations who still have some beta cell function.

The ability to process and secrete a mutant protein may predict a more benign course of the insulin mutation-related diabetes, but this possibility needs confirmation from studies in additional people with insulin gene mutations. A more severe diabetes phenotype may develop when insulin demands are high because of physiological stress, as observed in individuals with other types of insulin mutations that affect the processing proinsulin to insulin or mutations that reduce the affinity for the insulin receptor.

Acknowledgements We are grateful to the individual in this study for her participation. The authors of the study acknowledge laboratory technicians A. Mengel (Medical Research Laboratories, Aarhus University, Aarhus, Denmark) and K. Meyhoff-Madsen (ADME Department, Novo Nordisk, Måløv, Denmark) for invaluable assistance with the biochemical analyses and during the study day. Senior principal scientist T. Børglum Kjeldsen and principal laboratory technician A. Frost Bjerre (Recombinant Protein Technology, Novo Nordisk, Måløv, Denmark) are thanked for data from the insulin-receptor binding assay.

Data availability Data from the study are available from the corresponding author on request.

Funding The in vitro studies were supported by NIDDK grants P30 DK020595 and R01 DK10494 and by a gift from the Kovler Family Foundation.

Duality of interest JO and CUH are employees of, and own stocks in, Novo Nordisk. JS, S-YP, SG and GIB declare that there is no duality of interest associated with this manuscript.

Contribution statement All authors conceived and designed the study. JS, JO, CUH and S-YP collected and analysed the data. JS and JO wrote the first draft of the manuscript. All authors revised the manuscript critically and gave final approval of the submitted version. JS is the guarantor of the work.

\section{References}

1. Carmody D, Støy J, Greeley SA, Bell GI, Philipson LH (2016) A clinical guide to monogenic diabetes. In: Weiss RE, Refetoff S (eds) Genetic diagnosis of endocrine disorders, 2nd edn. Academic Press, Cambridge, pp 21-78

2. Støy J, EdghillEL, Flanagan SE etal (2007) Insulin gene mutations as a cause of permanent neonatal diabetes. Proc Natl Acad Sci U S A 104:15040-15044

3. Edghill EL, Flanagan SE, Patch AM et al (2008) Insulin mutation screening in 1,044 patients with diabetes: mutations in the INS gene are a common cause of neonatal diabetes but a rare cause of diabetes diagnosed in childhood or adulthood. Diabetes 57:1034-1042

4. Colombo C, Porzio O, Liu M et al (2008) Seven mutations in the human insulin gene linked to permanent neonatal/infancy-onset diabetes mellitus. J Clin Invest 118:2148-2156

5. Steiner DF, Tager HS, Nanjo K, Chan SJ, Rubenstein AH (1995) Familial syndromes of hyperproinsulinemia and hyperinsulinemia with mild diabetes. In: Scriver CR, Beaudet AL, Sly AS, Valle D (eds) The metabolic and molecular bases of inherited disease. McGraw-Hill, New York, pp 897-904

6. Molven A, Ringdal M, Nordbo AM et al (2008) Mutations in the insulin gene can cause MODY and autoantibody-negative type 1 diabetes. Diabetes 57:1131-1135

7. Boesgaard TW, Pruhova S, Andersson EA et al (2010) Further evidence that mutations in INS can be a rare cause of maturityonset diabetes of the young (MODY). BMC Med Genet 11:42

8. Meur G, Simon A, Harun N et al (2010) Insulin gene mutations resulting in early-onset diabetes: marked differences in clinical presentation, metabolic status, and pathogenic effect through endoplasmic reticulum retention. Diabetes 59:653-661

9. Dusatkova L, Dusatkova P, Vosahlo J et al (2015) Frameshift mutations in the insulin gene leading to prolonged molecule of insulin in two families with maturity-onset diabetes of the young. Eur J Med Genet 58:230-234

10. Polak M, Dechaume A, Cave $\mathrm{H}$ et al (2008) Heterozygous missense mutations in the insulin gene are linked to permanent diabetes appearing in the neonatal period or in early infancy: a report from the French ND (Neonatal Diabetes) Study Group. Diabetes 57:1115-1119

11. Rajan S, Eames SC, Park SY et al (2010) In vitro processing and secretion of mutant insulin proteins that cause permanent neonatal diabetes. Am J Physiol Endocrinol Metab 298:E403-E410

12. Park SY, Ye H, Steiner DF, Bell GI (2010) Mutant proinsulin proteins associated with neonatal diabetes are retained in the endoplasmic reticulum and not efficiently secreted. Biochem Biophys Res Commun 391:1449-1454

13. Izumi T, Yokota-Hashimoto $\mathrm{H}$, Zhao S, Wang J, Halban PA, Takeuchi T (2003) Dominant negative pathogenesis by mutant proinsulin in the Akita diabetic mouse. Diabetes 52:409-416

14. Yoshioka M, Kayo T, Ikeda T, Koizumi A (1997) A novel locus, Mody4, distal to D7Mit189 on chromosome 7 determines earlyonset NIDDM in nonobese C57BL/6 (Akita) mutant mice. Diabetes 46:887-894

15. Liu M, Sun J, Cui J et al (2014) INS-gene mutations: from genetics and beta cell biology to clinical disease. Mol Asp Med 42:3-18

16. Liu M, Hodish I, Haataja L et al (2010) Proinsulin misfolding and diabetes: mutant INS gene-induced diabetes of youth. Trends Endocrinol Metab: TEM 21:652-659

17. Johansen A, Ek J, Mortensen HB, Pedersen O, Hansen T (2005) Half of clinically defined maturity-onset diabetes of the young patients in Denmark do not have mutations in HNF4A, GCK, and TCF1. J Clin Endocrinol Metab 90:4607-4614

18. Glendorf T, Sorensen AR, Nishimura E, Pettersson I, Kjeldsen T (2008) Importance of the solvent-exposed residues of the insulin B chain alpha-helix for receptor binding. Biochemistry 47:4743-4751 
19. Andersen L, Dinesen B, Jorgensen PN, Poulsen F, Roder ME (1993) Enzyme immunoassay for intact human insulin in serum or plasma. Clin Chem 39:578-582

20. Dimas AS, Lagou V, Barker A et al (2014) Impact of type 2 diabetes susceptibility variants on quantitative glycemic traits reveals mechanistic heterogeneity. Diabetes 63:2158-2171
21. Krizkova K, Veverka V, Maletinska L et al (2014) Structural and functional study of the GlnB22-insulin mutant responsible for maturity-onset diabetes of the young. PLoS One 9:e112883

22. Menting JG, Yang Y, Chan SJ, et al. (2014) Protective hinge in insulin opens to enable its receptor engagement. Proc Natl Acad Sci USA 